\title{
CONTROLLED RELEASE OF THE ENCAPSULATED OF KARI (MURRAYA KOENIGII) LEAVE'S EXTRACT IN THE MATRIX OF GELATIN-GUM ARABIC
}

\author{
Jelita $^{1,2, *}$, Basuki Wirjosentono ${ }^{1, *}$,Tamrin ${ }^{1}$ and Lamek Marpaung ${ }^{1}$ \\ ${ }^{1}$ Department of Chemistry, Faculty of Mathematics and Natural Sciences, \\ Universitas Sumatera Utara, Medan, 20155, Indonesia \\ ${ }^{2}$ State Institute for Islamic Studies (IAIN)Langsa, Indonesia \\ *E-mail: jelitachemistry@gmail.com; basuki@usu.ac.id
}

\begin{abstract}
The characterization and the performance of Kari leave's extract that encapsulated with gelatin-gum Arabic have been evaluated. The encapsulated product was prepared using the spray drying method with a ratio of $0: 4 ; 3: 1 ; 2: 2$; $1: 3$ and 4:0. The encapsulated product with a ratio of $3: 1$ has the best properties, such as the lowest water content $(0.19 \%)$ and highest encapsulation efficiency $(91.90 \%)$. Based on the FT-IR spectra indicated the encapsulation process using a spray drying method does not lead to the formation of a new chemical bond. Also, the morphology of the encapsulated product at the ratio of 3:1 has the smallest particle size $(37-100 \mathrm{~nm})$. The controlled release property was observed from 0-80 minutes, the encapsulated product with a ratio of 3:1 has the highest value of content release $(69.37 \%)$ and the lowest value was showed by the encapsulated product with a ratio of 40:0 $(31.11 \%)$.
\end{abstract}

Keywords: Controlled released, Kari Leave's Extract, Gelatin, Gum Arabic, Spray Drying

(C) RASĀYAN. All rights reserved

\section{INTRODUCTION}

Murrayakoenigiiis a plant originated from India ${ }^{1}$, but at the present, this plant can be easily found in Province of Aceh, Indonesia. In Indonesia, it is known as Kari, but in Aceh it has a local name, Temurui. The Kari leave has been widely used as spice ingredients that are used as food seasonings because of their distinctive aroma ${ }^{2}$.The Kari leave can be used as the antioxidant, antibacterial, antifungal, anticancer, antidiabetic and anti-hypertensive ${ }^{3-5}$. Those powerful activities of Kari leaves are influenced by the presence of the following components, such as $\beta$ pinene, $\beta$ - caryophyllene, $\beta$ - phellandrene and $\alpha$ - pinene, also these compounds have a role to control food from spoiled and give a unique flavor ${ }^{6}$.

The compound that constructs the unique flavor is classified into volatile components. As a volatile component, naturally that component will have relatively high volatility and are chemically unstable. To prevent the loss of volatile component in Kari leaves, a method that able to control the stability, retention and release of Kari flavors is urgently needed.

Encapsulation technology has been developed to protect flavors from evaporation and degradation in the food industry. ${ }^{7-11}$ Also, the encapsulation process can prevent the core material from the oxidation process. ${ }^{12-14}$ These technologiesinvolve trapping the flavor molecules within colloidal particles specifically designed to inhibit their volatilization and degradation duringstorage and cooking ${ }^{15}$. The property of the encapsulated product is dependent on many factors, such as the properties of Kari leave's components, the matrix in the encapsulation process, etc. ${ }^{16,17}$

Rasayan J. Chem., 12(3), 1157-1165(2019)

http://dx.doi.org/10.31788/RJC.2019.1235378

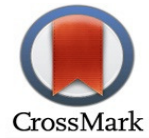


In this study will be focused on the utilization of biopolymer a combination of protein and polysaccharide to encapsulate extract of Kari leave to the physical properties of the encapsulated product. These two biopolymers were suggested as good material for encapsulation material ${ }^{18}$. Gelatin as biopolymer has a good emulsion capacity, soluble in water and stable ${ }^{19}$.In the other hand, gum arabic as hetero-polysaccharide has a good emulsion property and low viscosity ${ }^{20}$. The encapsulation process will be prepared using spray drying method because of some advantages, such as (i) the obtained powder has good quality, (ii) water content is low, (iii) easy to store and (iv) able to protect the active component from the unwanted reaction ${ }^{21-25}$. The main objective of this research was to evaluate whether the blend of gelatin and gum arabic could be used to control the flavor released. Also, the properties of the obtained microcapsule in this study by spray drying method have been evaluated includingthe yield of the microcapsule, water content, the efficiency of the microcapsule, FT-IR spectra, SEM, TEM, and release properties of Kari leave.

\section{Materials}

\section{EXPERIMENTAL}

Kari leave was obtained from Sungai Pauh village, Langsa, Aceh. The extract of Kari leave was prepared using maceration technique. Gelatin as the coating material was extracted from beef bones (Os Scapula) were obtained from the Slaughterhouses Langsa Aceh using the acid hydrolysis method. Gum Arabic was purchased from CV. Rudang Jaya Medan, Sumatera Utara Indonesia.

\section{Instrumentation}

The functional group of microcapsule component was determined using FT-IR Perkin Elmer 1600 series. The morphology and particle size of the obtained microcapsule were observed using SEM JEOL model JSM-S410LV and Transmission Electron Microscopy JEOL JEM 1400. The controlled release property of Kari leaves extract from the microcapsule matrix was evaluated using spectrophotometer UV-Vis Shimadzu UV-1600 A.

\section{Procedure}

\section{Encapsulation Process of Kari Leave's Extract}

The encapsulation process was conducted using spray drying in the following method with some modification $^{26,27}$. The emulsion formation of Kari leaves for the encapsulation process was prepared by $40 \%$ of encapsulating material and $10 \%$ of Kari leave's extract, where the ratio of gelatin and gum arabic was 40:0, 30:10, 20:20, 10:30, and 0:40. For the example, to prepare the Kari leave's microcapsule with 1:1 of ratio was started by the dissolution of $20 \mathrm{~g}$ of gelatin and gum arabic with $100 \mathrm{~mL}$ of distilled water in a separated beaker. Those solutions were mixed up, into this solution $10 \mathrm{~g}$ of Kari leave's extract and $1 \mathrm{~g}$ of Tween80 were added and stirred for 5 minutes. The emulsion of Kari leave's extract was homogenized at $5000 \mathrm{rpm}$ for 20 minutes. The obtained solution was diluted with $300 \mathrm{~mL}$ of distillated water and followed by spray drying process using Buchi model Mini spray dryer B-290, that operated under inlet and outlet temperaturewere 125 and $60^{\circ} \mathrm{C}$, respectively and pump speed was $1000 \mathrm{rpm}$.

\section{The Yield of Microcapsule}

The yield percentage of Kari leave's microcapsule that obtained through spray drying method was determined by comparing the weight of microcapsule and weight of solid total before drying process $^{28}$.

$\% \mathrm{R}=\frac{\mathrm{M} 1}{\mathrm{M} 2} \times 100 \%$ 
Where

$\mathrm{R} \quad=$ Yield percentage

M1 = weight of microcapsule $(\mathrm{g})$

M2 = weight of solid total before the drying process $(\mathrm{g})$

\section{Water Content}

The evaporating dish was placed in the oven at $105^{\circ} \mathrm{C}$ of temperature for $2 \mathrm{~h}$. The dried evaporating dish was weighed, and $1 \mathrm{~g}$ of microcapsule was placed in this evaporating dish. The evaporating dish then placed in the oven at $105^{\circ} \mathrm{C}$ of temperature for $2 \mathrm{~h}$ and cooled in a desiccator. This evaporating dish weighed several times until the constant weight was obtained. The water content was determined using the following equation ${ }^{29}$.

$\% W=\frac{M_{1}-M_{2}}{M_{1}} x 100 \%$

Where:

$\mathrm{W}=$ the water content

$\mathrm{M}_{1}=$ the weight of microcapsule before drying process

$\mathrm{M}_{2}=$ the weight of microcapsule after drying process

\section{The Efficiency of the Encapsulation Process}

Microcapsule $(500 \mathrm{mg}$ ) was dissolved in $30 \mathrm{~mL}$ of $\mathrm{n}$-hexane using mechanical stirrer for 2 minutes. The filtrate was separated, and $30 \mathrm{~mL}$ of $\mathrm{n}$-hexane was added into the residue. The obtained filtrate was collected in an Erlenmeyer that has been weighed, the n-hexane was evaporated at $70^{\circ} \mathrm{C}$ of temperature until the weight was constant. The surface oil was determined from the weight difference of the empty Erlenmeyer and the Erlenmeyer after the evaporation process. The oil total was determined based on the weight of the encapsulation product. Thus, the efficiency of encapsulation process of Kari leave's extract can be calculated using the equation below $^{27,30}$.

$\mathrm{EE}=\frac{\mathrm{Wt}-\mathrm{Ws}}{\mathrm{Wt}} \times 100 \%$

Where,

$\mathrm{EE} \quad=$ the efficiency of encapsulation

$\mathrm{Wt}=$ the mass of oil total

Ws $=$ the mass of surface oil

\section{Fourier-Transform Infrared Spectroscopy (FTIR)}

The functional group that presence in the Kari leave's microcapsule was determined using FT-IR Perkin Elmer 1600 series in the range $4000-600 \mathrm{~cm}^{-131}$.

\section{Scanning Electron Microscopy}

The surface of Kari leave's microcapsule was analyzed using Scanning Electron Microscopy(JEOL model JSM-S410LV, Japan). The microcapsule was coated with gold and palladium.

\section{Transmission Electron Microscopy}

The surface of Kari leave's microcapsule was determined using Transmission Electron Microscopy (JEOL JEM 1400). The obtained image was analyzed using ImageJ to determine the particle size of the microcapsule ${ }^{32}$. 


\section{Controlled Release Property}

The controlled release process was determined using the following methods ${ }^{33,34}$. The ability of Kari leave's extract to release from the microcapsule matrix was evaluated using UV-Vis (Shimadzu UV-1600 A). Microcapsule ( $0.5 \mathrm{~g}$ ) was dissolved in $10 \mathrm{~mL}$ of methanol. The mixture was stirred at $30^{\circ} \mathrm{C}$ of temperature until the end of the evaluation process. The aliquot $(5 \mathrm{~mL})$ was taken every 10 minutes and the absorbance was determined using UV at $228 \mathrm{~nm}$. The Kari leave's concentration obtained during this process was determined using a calibration curve.

\section{Kari leave's Microcapsule}

\section{RESULTS AND DISCUSSION}

The Kari leave's microcapsule was prepared using a combination of the coating agent, such as gelatin and gum arabic. The obtained microcapsule has different physical properties, especially the color of the microcapsule. The difference of microcapsule color is influenced by the difference in coating agent ratio. The color concentration of each microcapsule can be seen in Table-1.

Table-1:The Color Concentration of Microcapsule

\begin{tabular}{c|c|c|c|c}
\hline \multirow{2}{*}{ No } & \multicolumn{2}{|c|}{ The ratio of Coating Agent (\%) } & Core Material (\%) & $\begin{array}{c}\text { Color } \\
\text { Concentration }\end{array}$ \\
\cline { 2 - 5 } & Gelatin & Gum Arabic & Kari leave's Extract & + \\
\hline 1 & 40 & 0 & 10 & ++++ \\
\hline 2 & 30 & 10 & 10 & +++ \\
\hline 3 & 20 & 20 & 10 & ++ \\
\hline 5 & 10 & 30 & 10 & ++ \\
\hline
\end{tabular}

Based on Table-1, the stronger microcapsule color is obtained in the ratio of 30:10 (gelatin/ gum arabic) and the weaker is shown by microcapsule with the ratio 40:0 (gelatin/gum arabic). This phenomenon can be caused by the property of gelatin that able to absorb the green color of Kari leave's extract. Also, the presence of gum arabic in the exact amount can make that property be stronger.

\section{Yield and Water Content of Microcapsule}

The yield of microcapsule was obtained by comparing the weight of a solid total before and after the encapsulation process. The difference in the yield percentage is influenced by the emulsion characteristic during the homogenizing step. The high viscosity of gelatin has a big impact on this phenomenon. The high viscosity will cause the spraying process to be more difficult and most of the solid content will attach at the instrument, this will result in the low yield of microcapsule will be obtained. The yield percentage of Kari leave's microcapsule was shown in Table-2. The highest yield percentage is obtained at a ratio of 10:30 (gelatin/ gum arabic) and the lowest at a ratio of 40:0. These values show that the viscosity of the coating agent has a big influence on the yield percentage. In Table- 2 also presence the water content of microcapsule.

Table-2:Yield Percentage and Water Content of the Microcapsule

\begin{tabular}{|c|c|c|c|c|c|}
\hline \multirow{2}{*}{ No } & \multicolumn{2}{|c|}{ The ratio of Coating Agent } & \multirow{2}{*}{$\begin{array}{c}\text { Core Material } \\
\text { Kari leave's Extract }\end{array}$} & \multirow{2}{*}{$\begin{array}{c}\text { Yield } \\
(\%)\end{array}$} & \multirow{2}{*}{$\begin{array}{c}\text { Water } \\
\text { Content } \\
(\%)\end{array}$} \\
\hline & Gelatin & Gum Arabic & & & \\
\hline 1 & 40 & 0 & 10 & 20.72 & 0.79 \\
\hline 2 & 30 & 10 & 10 & 27.24 & 0.19 \\
\hline 3 & 20 & 20 & 10 & 26.68 & 0.78 \\
\hline 4 & 10 & 30 & 10 & 28.54 & 0.18 \\
\hline 5 & 0 & 40 & 10 & 20.84 & 0.20 \\
\hline
\end{tabular}


Based on Table-2, the water content of the microcapsule is about $0.18-0.79 \%$. This result showed a similar result with the previous work ${ }^{35}$. This water content can be classified as low water content ${ }^{27}$. The lowest water content of a product, the possibility of the contamination of bacterial and oxidation of fatty acid will be lower.

\section{The Efficiency of the Encapsulation Process}

The efficiency of encapsulation shows the number (percentage) of Kari leave's extract that presence in the microcapsule. The higher the efficiency of the encapsulation process, the higher the Kari leave's extract that entrapped in the microcapsule. In this work, the highest efficiency is shown by the formulation of 30:10 (gelatin/ gum arabic) with a value of 91.90\% (Table-3).

Based on the efficiency result, there are some of Kari leave's extract that not coated by the coating agent. This was influenced by the chosen method to produce encapsulated material, in this case, spray drying method. This method uses hot steam in the atomization process that has an impact on the number of Kari leave's extract in the microcapsule matrix. The other factor, i.e. the ratio of coating agent in the formulation has a big impact on the efficiency of the encapsulation process. The increase of gelatin content can increase the efficiency of the encapsulation process. This effect has a correlation to the viscosity of gelatin, the highest viscosity has an impact on the ability of coating agent to bind the particle during the emulsion formation. This efficiency value has a similar result with the previous work ${ }^{36}$, it is about $93.2 \%$. That research showed the increase in efficiency is caused by the increasing the number of whey protein. That is similar to this research, the increase in the number of gelatins can increase the efficiency of the encapsulated material.

Tabel-3:Efficiency of the Encapsulation Process

\begin{tabular}{c|c|c|c}
\hline \multirow{2}{*}{ No } & \multicolumn{2}{|c|}{ The ratio of Coating Agent (\%) } & \multirow{2}{*}{ EE (\%) } \\
\cline { 2 - 3 } & Gelatin & Gum arabic & \\
\hline 1 & 40 & 0 & 81.10 \\
\hline 2 & 30 & 10 & 91.90 \\
\hline 3 & 20 & 20 & 87.80 \\
\hline 4 & 10 & 30 & 85.70 \\
\hline 5 & 0 & 40 & 80.80 \\
\hline
\end{tabular}

\section{FT-IR of Microcapsule}

Figure-1 for gum arabic spectrum showed vibration of O-H stretching at $3402 \mathrm{~cm}^{-1}$ that represent the saccharide in gum arabic. The vibration of $\mathrm{C}-\mathrm{H}$ stretching is confirmed at $2931 \mathrm{~cm}^{-1}$. The $\mathrm{C}=\mathrm{C}$ of the aromatic group is found at $1604 \mathrm{~cm}^{-1}$. The other signal is found at $1072 \mathrm{~cm}^{-1}$ that confirmed the presence of C-O stretching from C-O-C of ether or C-O-H of alcohol.

Gelatin spectrum showed some signals at 3394 and $1651 \mathrm{~cm}^{-1}$ that confirm the presence ofthe vibration of hydroxyl and amide group. The signal of the amino group could not be found due to the shape of the O-H signal. The presence of amide group on that position was confirmed by the similar result that obtained by Tam et al. ${ }^{37}$ That signal was found as alginate-poly-L-lysine at 1645 and $1540 \mathrm{~cm}^{-1}$.

The other hand, Kari leave's extract also showed the vibration of $\mathrm{O}-\mathrm{H}$ stretching at $3387 \mathrm{~cm}^{-1}$. The signal of $\mathrm{C}-\mathrm{H}$ stretching can be found at $2924 \mathrm{~cm}^{-1}$. The other signal also found at $1620 \mathrm{~cm}^{-1}$, that confirm the presence of $\mathrm{C}=\mathrm{C}$ stretching. The spectrum of microcapsule showed several signals at 3387, 3749, 2916 and $2864 \mathrm{~cm}^{-1}$ that indicated the presence of $\mathrm{O}-\mathrm{H}$ stretching, $\mathrm{N}-\mathrm{H}$ stretching, $\mathrm{C}-\mathrm{H}$ stretching and bending, respectively. The other signal also found such as 1697 and $1072 \mathrm{~cm}^{-1}$ that indicated the presence of $\mathrm{C}=\mathrm{O}$ from the carboxylic group and $\mathrm{C}-\mathrm{O}$ stretching from alcohol, respectively. During the encapsulation process and based on the FT-IR spectra can be concluded that there is no chemical reaction that occurred, because there is no new signal is found ${ }^{33,38}$.

\section{Morphology of Microcapsule}

The Kari leave's microcapsule was observed using SEM for the particle morphology and distribution (Fig.-2). 
RASĀYAN J. Chem.

Vol. 12 | No. 3 |1157 - 1165| July - September | 2019

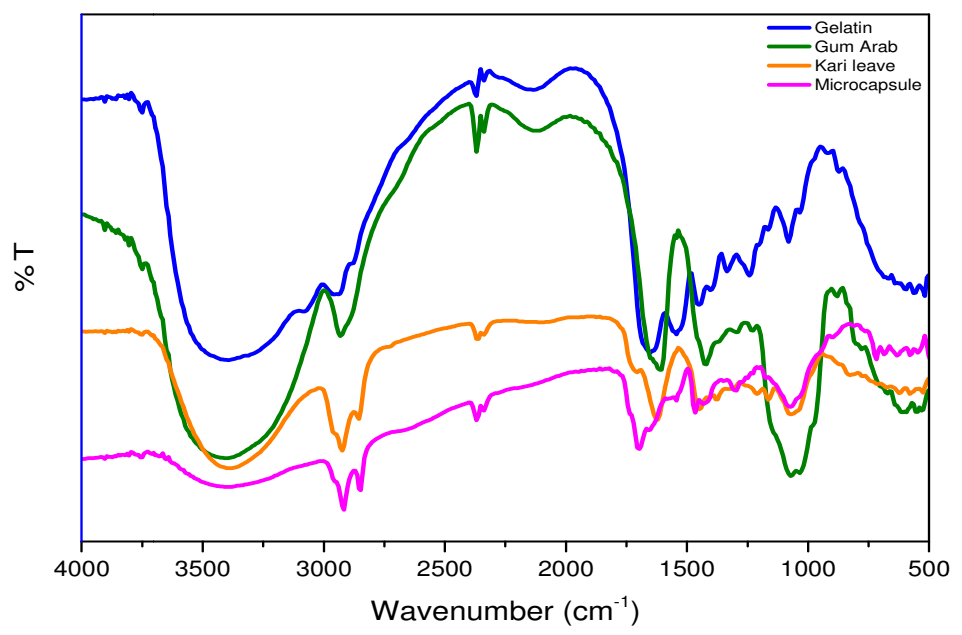

Fig.-1: FT-IR Spectra of Gum Arabic, Gelatin,Kari Leave's Extract and Microcapsule

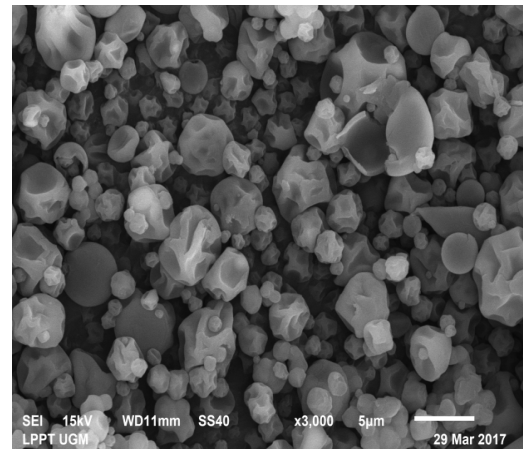

(A)

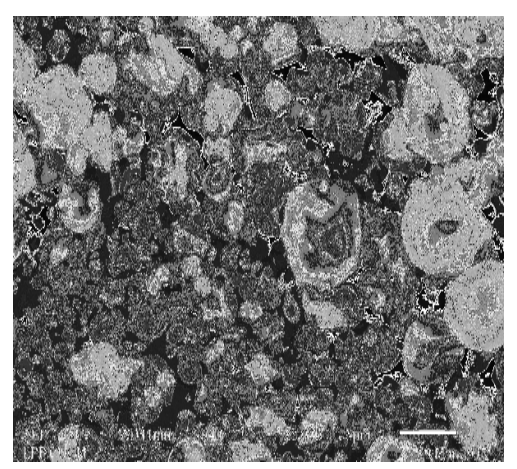

(B)

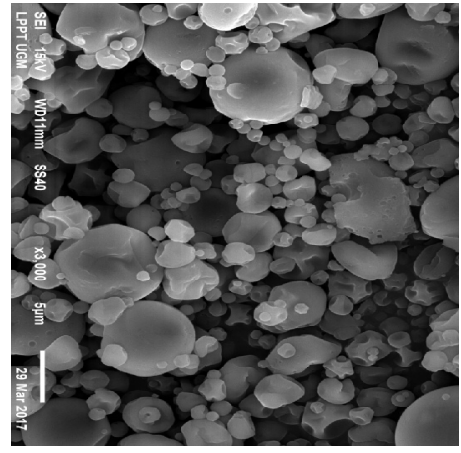

(C)

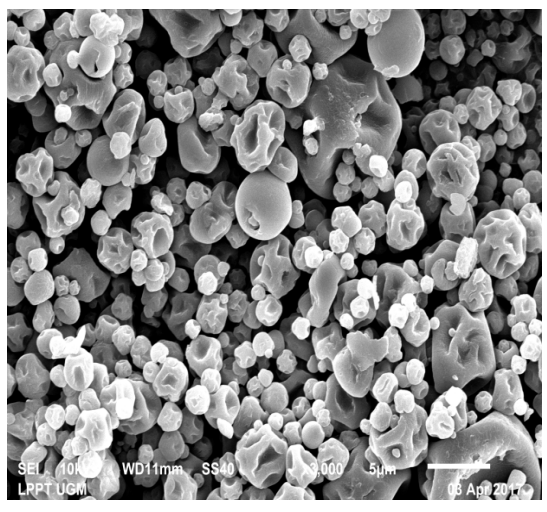

(D)

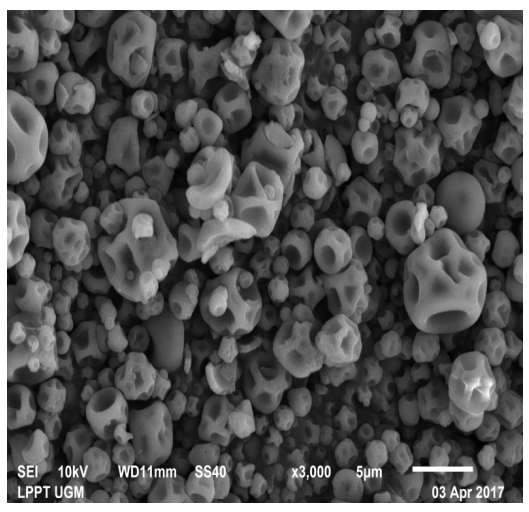

(E)

Fig-2:SEM images of Kari Leave's Microcapsule (A) 40:0, (B) 30:10, (C) 20:20, (D) 10:30, and (E) 0:40

The morphology of microcapsule shows the different result due to the different composition, but at all kind of ratio, the particle has a wrinkle on the surface. The influence of composition on the morphology of microcapsule also declared byRajabi et $\mathrm{al}^{18}$. The difference in distribution particle size based on SEM images, mostly caused by the stirring speed during the homogenization process. The wrinkle that obtained at the particle surface is caused by the hot steam during the atomization step of spray drying $\operatorname{process}^{18}$.The temperature setting during spray drying also has a big impact on the particle size distribution ${ }^{35}$. 


\section{Particle Size of Microcapsule}

Based on TEM analysis (Fig.-3), the microcapsule has an irregular shape and found as an agglomerate. The particle size analysis was determined using ImageJ, the result was displayed in Table-4. Based on Table-4, the particle size of the microcapsule is increased with the increasing of the gum arabic concentration. The biggest particle size is found in the ratio of 0:40 with a particle size of $593 \mathrm{~nm}$. The same result was obtained by Edris ${ }^{27}$, the high viscosity of gum arabic influenced the particle size and mostly found as an agglomerate and gave irregular shape. The smallest particle size is found in the ratio of 40:0 with a particle size of $76.51 \mathrm{~nm}$. The obtained shape at this ratio is irregular and found as agglomerate, this is caused by the viscosity of gelatin. The difference result is obtained at the ratio 30:10, at this ratio the microcapsule particle has rounded shape and mostly found in homogenous size. The ratio of 30:10 give a bigger particle size than 40:0, that is $87.62 \mathrm{~nm}$.

Table-4: Particle Size of Kari Leave's Microcapsule

\begin{tabular}{c|c}
\hline $\begin{array}{c}\text { Ratio } \\
\text { Gelatin:Gum Arabic }\end{array}$ & Particle size (nm) \\
\hline $0: 40$ & $593.14 \pm 223.17$ \\
\hline $30: 10$ & $87.62 \pm 47.38$ \\
\hline $40: 0$ & $76.51 \pm 15.70$ \\
\hline
\end{tabular}

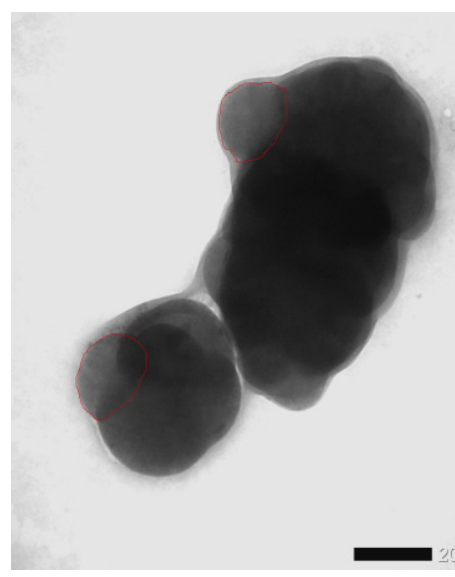

A $(0: 40)$

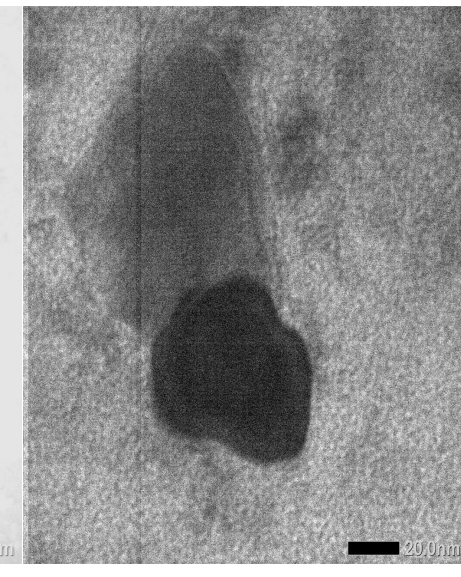

B (40:0)

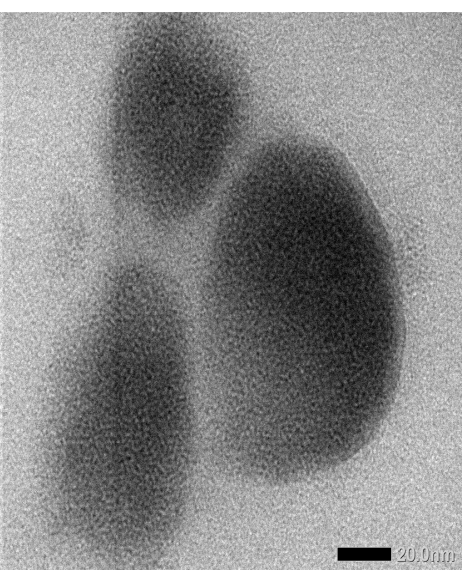

C $(30: 10)$

Fig.-3: TEM Images of Kari Leave's Microcapsule

\section{Controlled Release}

The controlled release measurement is conducted to determine the amount of Kari leave's extract that able to release from the matrix. The result of three models $(0: 40,30: 10$ and 40:0) for controlled release measurement is shown in Table-5. The highest value is obtained at the ratio of 30:10 after 80 minutes with value $69.37 \%$ and the lowest result is obtained at the ratio of 40:0.

Tabel-5. Controlled release of microcapsule

\begin{tabular}{c|c|c|c|c}
\hline \multirow{2}{*}{$\begin{array}{c}\text { Ratio of } \\
\text { Gelatin:Gumarab(\%) }\end{array}$} & Corematerial(\%) & Minute & Absorbance & Concentration(\%) \\
\hline \multirow{2}{*}{$40: 0$} & \multirow{3}{*}{10} & 10 & 0.265 & 31.11 \\
\cline { 3 - 5 } & \multirow{2}{*}{$30: 10$} & 20 & 0.273 & 32.17 \\
\cline { 3 - 5 } & & 40 & 0.328 & 39.51 \\
\cline { 3 - 5 } & \multirow{2}{*}{10} & 80 & 0.330 & 39.77 \\
\hline \multirow{2}{*}{30} & & 10 & 0.392 & 48.04 \\
\hline
\end{tabular}


RASĀYAN J. Chem.

Vol. 12 | No. 3 |1157 - 1165| July - September | 2019

\begin{tabular}{c|c|c|c|c}
\hline \multirow{2}{*}{$0: 40$} & & 40 & 0.497 & 62.04 \\
\cline { 3 - 5 } & & 80 & 0.552 & 69.37 \\
\hline \multirow{4}{*}{0} & 10 & 0.28 & 33.11 \\
\cline { 3 - 5 } & \multirow{4}{*}{10} & 20 & 0.298 & 35.51 \\
\cline { 3 - 5 } & & 40 & 0.302 & 36.04 \\
\cline { 3 - 5 } & & 80 & 0.408 & 50.17 \\
\hline
\end{tabular}

CONCLUSION

Based on FTIR results, there is a shift in the wave number of the functional groups, but it does not change the existing functional groups and no new chemical bonds are found between the spectrum of microcapsules and wall material but rather electrostatic interactions. The best Kari leave extract microcapsules were found in gelatin: gum Arabic (30:10) with $0.19 \%$ moisture content, $27.24 \%$ yield and encapsulation efficiency value of $91.90 \%$. The form of microcapsules of Kari leave extract has an almost round shape, slightly wrinkled and spread less evenly. The particle size of microcapsules ranges from $76.51 \pm 15.70 \mathrm{~nm}-593.14 \pm 223.17 \mathrm{~nm}$. The core release test results showed the highest value is obtained at the ratio of $30: 10$ after 80 minutes with value $69.37 \%$ and the lowest result is obtained at the ratio of 40:0.

\section{REFERENCES}

1. A. Nayak, S. Mandal, A. Banerji, and J. Banerji, J. Chem. Pharm. Res., 2, 286(2010), DOI: 10.20959/wjpps20172-8740

2. M.B. Ningappa, R. Dinesha, and L. Srinivas, Food Chem., 106, 720(2008), DOI: 10.1016/j.foodchem.2007.06.057

3. G.A. Ajay S, Rahul S, SumitG , Paras M, Mishra A, Asian J. Pharm. Anf. Life Sci., 1, 417(2011).

4. H. Al Harbi, U.M. Irfan, and S. Ali,European Journal of Pharmaceutical and Medical Research, 3, 382(2016).

5. D. Iyer and U.P. Devi, Pharmacogn. Rev., 2, 180(2008).

6. C. Sivakumar and I. Meera, J. Food Process. Technol., 4, (2013), DOI: 10.4172/2157-7110.1000246

7. P. Achinna and T. Nadu, J. Res. Angrau., 38, 86(2010).

8. J. Milanovic, V. Manojlovic, S. Levic, N. Rajic, V. Nedovic, and B. Bugarski, Sensors, 10, 901(2010), DOI: 10.3390/s100100901

9. J.S.R.I. S, A. Seethadevi, K.S. Prabha, and P. Muthuprasanna, Int. J. Pharm. Bio., 3, 509(2012).

10. K.P.S. Kumar, S. Tejbe., S. Banu, P.N. Lakshmi, and D. Bhowmik, Indian J. Res. Pharm. Biotechnol., 1, 324(2013).

11. H. Umer, H. Nigam, A. Tamboli, and M. Nainar, Int. J. Res. Pharm. Biomed. Sci., 2, 474(2011).

12. S. More, J. Gade, and J. Waghmare, Asian J. Sci. Technol., 6, 1902(2015).

13. K.P.R. Chowdary, P. Mohapatra, and M.N.M. Krishna, Rasayan J. Chem., 1, 99(2008).

14. A. Sukmawati, A. Nafarin, R. Yuliani, W. Utami, M. Da'i, and N. Aini, Rasayan J. Chem., 11, 1657(2018), DOI: 10.31788/RJC.2018.1144084

15. S. Krishnan, A.C. Kshirsagar, and R.S. Singhal, Carbohyd. Polym., 62, 309(2005), DOI: 10.1016/j.carbpol.2005.03.020

16. S.F. Pang, M.M. Yusoff, and J. Gimbun, Food Hydrocoll., 37, 159(2014), DOI: 10.1016/j.foodhyd.2013.10.022

17. S.M. Jafari, E. Assadpoor, Y. He, and B. Bhandari, Dry. Technol., 26, 816(2008), DOI: 10.1080/07373930802135972

18. H. Rajabi, M. Ghorbani, S.M. Jafari, A. SadeghiMahoonak, and G. Rajabzadeh, Food Hydrocoll., 51, 327(2015), DOI: 10.1016/j.foodhyd.2015.05.033

19. B. Shu, W. Yu, Y. Zhao, and X. Liu, J. Food Eng., 76, 664(2006), DOI: 10.1016/j.jfoodeng.2005.05.062

20. R. Shaddel, J. Hesari, S. Azadmard-damirchi, H. Hamishehkar, B. Fathi-achachlouei, and Q.Huang, Int. J. Biol. Macromol., 107, 1800(2018), DOI: 10.1016/j.ijbiomac.2017.10.044 
21. J.H. Ahn, Y.P. Kim, Y.M. Lee, E.M. Seo, K.W. Lee, and H.S. Kim, Food Chem., 107, 98(2008), DOI: 10.1016/j.foodchem.2007.07.067

22. D. Kanakdande, R. Bhosale, and R.S. Singhal, Carbohyd. Polym., 67, 536(2007), DOI: 10.1016/j.carbpol.2006.06.023

23. Y. Wang,Z. Lu, andF. Lv, Eur. Food Res. Technol.,229(3), 391(2009), DOI: 10.1007/s00217-0091064-6

24. S. Ersus and U. Yurdagel, J. Food Eng., 80, 805(2007), DOI: 10.1016/j.jfoodeng.2006.07.009

25. R. Partanen, J. Raula, R. Seppanen, J. Buchert, E. Kauppinen, and P. Forssell, J. Agric. Food Chem., 56, 5717(2008), DOI: $10.1021 / \mathrm{jf} 8005849$

26. R. Castro-Muñoz, B.E. Barragán-Huerta, and J. Yáñez-Fernández, LWT - Food Sci. Technol., 62 , 242(2015), DOI: 10.1016/j.lwt.2014.09.042

27. A.E. Edris, D. Kalemba, J. Adamiec, and M. Piaotkowski, Food Chem., 204, 326(2016), DOI: 10.1016/j.foodchem.2016.02.143

28. F. Xue, C. Li, Y. Liu, X. Zhu, S. Pan, and L. Wang, 119, 439(2013), DOI: /10.1016/j.jfoodeng.2013.06.012

29. D. V. Mendanha, S.E. Molina Ortiz, C.S. Favaro-Trindade, A. Mauri, E.S. MonterreyQuintero, and M. Thomazini, Food Res. Int., 42, 1099(2009), DOI: 10.1016/j.foodres.2009.05.007

30. P. Roccia, M.L. Martínez, and J.M. Llabot,Powder Technology, 254, 307(2014), DOI: 10.1016/j.powtec.2014.01.044

31. G.A. Rocha-selmi, F.T. Bozza, M. Thomazini, H.M.A. Bolini, and C.S. Fávaro-trindade, Food Chem., 139, 72(2013), DOI: 10.1016/j.foodchem.2013.01.114

32. I.P. Mahendra, B. Wirjosentono, Tamrin, H. Ismail, and J.A. Mendez, Rasayan J. Chem., 12, 635(2019), DOI:10.31788/RJC.2019.1225089

33. N. Devi, D. Hazarika, C. Deka, and D.K. Kakati, J. Macromol. Sci. Part A Pure Appl. Chem., 49, 936(2012), DOI: 10.1080/10601325.2012.722854

34. L.C. de Conto, C.R.F. Grosso, and L.A.G. Gonçalves, LWT - Food Sci. Technol., 53, 218(2013), DOI: 10.1016/j.Iwt.2013.02.017

35. R. Wang, Z. Tian, and L. Chen, Food Research International, 44, 2735(2011), DOI: 10.1016/j.foodres.2011.06.013

36. Y. Wang, W. Liu, X. Dong, and C. Selomulya, J. Food Eng., 175, 74(2016), DOI: /10.1016/j.jfoodeng.2015.12.007

37. S.K. Tam, J.Dusseault, S. Polizu, M. Me, L.H. Yahia, and J. Halle,Biomaterials,26, 6950(2005), DOI:10.1016/j.biomaterials.2005.05.007

38. X.Y. Qv, Z.P. Zeng, and J.G. Jiang, Food Hydrocoll., 25, 1596(2011), DOI: 10.1016/j.foodhyd.2011.01.006

[RJC-5378/2019] 